\title{
The Original Identity of the Safavid (Mosque) In Isfahan
}

\author{
Jamaleddin Mahdinejad
}

Assistant Professor, faculty Architecture and Urbanism, Shahid Rajaee Teacher Training University of Tehran

Marzieh Etemadi Pour*

Ph.D. student, Shahid Rajaee Teacher Training University of Tehran

Email:m.etemadipur@gmail.com

\section{Doi:10.5901/mjss.2015.v6n6s6p242}

\section{Abstract}

Kafran is among villages of the general region of Rouydasht, at the extreme eastern end of Isfahan province, having a long past, due to it'sexisting documents. The present study, being just a part of the whole program known as development of the history of Iranian architecture, tries to uncover the identity and development of the Mosque. Todo this, and with the aid of librarian and field studies, we shall try to investigate this structure attributed to Safavid period, by representing a description of its features, through maps. These are followed by some architectural analyses, according to which it is found that the southern nave is nothing more than a later addition to the original building. This hypothesis may be proved through employing such arguments as the "non-existence of" the mentioned space in the initial design of the structure; therefore one may conclude that the initial using of the original building had not been religious at all. Other [visual] evidences corroborate our hypothesis; among them one can mention the lack of form, scale and shape proportions of the main (northern)nave for performing "prayer ceremony, unsuitability of first story spaces for usual functions of mosques, lack of historical precedence for the model in the known Iranian History of mosque building, and etc. Ultimately it should be noted that the original nucleus of Hadji mosque is very similar to Safavid pavilions, and thus one may put forward the proposal that the original nucleus of the structure might have been of "formal-ceremonial, or -administrative" type.

Keywords: Hadjimosque architecture, Isfahanvillage of Kafran, development, original/ initial function.

\section{Questions to be Answered}

1. Do all spatial and physical parts of the building [formally] Known as HadjiKafran Mosque, really belong to a single time-interval, or instead, one can identify changes within the structure during a long time?

2. Can we consider an original religious using for the monument, or instead, it's using had been something differentfrom one people nowadays consider it to be?

3. What is the most probable using for the original nucleus of the building?

\section{Introduction}

One of the Key elements of the study of Iran's general social history is the data obtained from a precise, systematic and large-scale investigation of villages as various parts of the country; as the collection of these detailed data can provide a useful source for this importantaspect of the history of Iran on the basis of modern researches (BastaniParizi, 1997:1). Any attempt for completion and clarification of history of architecture, as a key aspect of social history of Iran, should be considered as an extreme priority of research programs. It is precisely for this purpose that the present study selects the architecture of Hadjimosque of safavid period, located at the village of Kafran, in ancient region of Rouydasht, at the eastern end of Isfahan province (Ashrafi, 2006). As an introduction to enter the main issue of the subject, namely the clarification of the original identity as well as time development of the building, a brief glance to the history and geographical history of Rouydashtand the village of Kafran is presented. The main hypothesis of the study is the fact that the greater space of the mosque, namely the southern nave [Shabestan in Persian], is alater addition: the hypothesis is to be proven through a number of arguments. This proof, together with other reasons delivered bellow, suffices for the validity of our assertion, namely the fact that the original nucleus of the mosque didn't enjoy any sort of religious using. It is tried through comparative study of similar monuments to answer one of the most fundamental questions of the study; 
namely, what was the original using of the building.

The study has been undertaken by the aid of historical and Analytical methods, alongside with the aid of field, as well as of library surveys. Our priority has been to use the "first-hand" or primary sources, which means those books written by early Islamic Period Authors. In spite of publication of a number of papers concerning Rouydashtregion monument (Salehi Kakhaki, 2008), few attention has been paid until now to those of Kafran village; and this too contributes to the necessity of doing research on the subject.

\section{A Review of History and Geography of Rouydasht}

Though geographical divisions of Isfahan [province] had been varied over the periods, but the name of Rouydasht has always been attested; as for example in Book of Al-Isfahan, Rouydashtis mentioned among one of 20 Blocks [geographical divisions] of Isfahan (Jenablsfahani, 1924:140). It was the last block in the course of Zayandeh-rud which terminates at Gav-Khuni marsh (Sotudeh, 1963:37). The region has been flourished from remote pasts due to existence of its alluvial soil, warm weather as well as Zayandeh-rud water sources (HosseiniAbari,2000:159). It is cited in the book of "half of the world in description of Isfahan" that: "Rouydasht's length from east to west approximates some 12 Farsakhs (a Persian unit of length, equals seven Kms) and it's width measures about 4; And lands within the area are fertile and filled with cereals"(Isfahani,1989:43). The region is also mentioned in traditional history of Iran, within the biography of Tamurath of Pishdadidynasty (Ibn-e-Faghih,1970 : 100). Some monuments and objects from $3^{\text {rd }}$ to $1^{\text {st }}$ millennium B.C. have been found in the historical mound of Kupandeh [=Kupandetappeh ], showing the settling of the earliest villagers at the banks of Zayandeh-rudand also within the Iranian plateau (salehikakhaki 2008). Towardsthe end of Sasanianera, Rouydasht has been a military base of the Persians, as we read that Piruz, son of Yazdgerd the $3^{\text {rd }}$ and the ruler of the region, when confronted with Arab invasion, fled to Rouydasht and constructed a base at the city of Parpan (farfan village of present times). He then ruled over the region of Garkuyehand Rouydasht, as long as their people remained as Zoroastrians (Bastani Parizi, 1997: 124) (RajaeiZefrei1997).

Some of early Islamic period sources have mentioned Rouydasht and Jeyas villages of Isfahan (Ibn-eKhordazbeh,1991:19) (AbuNa'imlsfahani,1998:44) (Ibn-e-Rosteh, 1986:67). Other sources have also attested the significance of this region in the early Islamic period and in Saljuq erain particular; as we read in" History of Isfahan" book: "Deylamians had two important and special city- citadels in Isfahan nearby; the first was Firuzan-e-Lenjan in the both sides of Zayandeh-rud,and the second was Farfaran-e-Rouydasht"(JaberiAnsari, 1999:11). Rouydasht and the village of Farfaran in particular, preserved their importance up to $14^{\text {th }}$ century A.D.namely at the time of Ilkhananthe Mongoloids, when it was mentioned as a large city (Mostofi, of 14th century A.D: 69). The region was also a part of Safavid head-quarter at the late times of that period (Bastani Parizi, 1997: 171-193).

Kafran is one of the sub-villages of Rouydasht region. At the Safavid Period it was quite flourished, as is evidenced from the existence of a number of mosques such as those of Jame'h, Hadjiand Bazar.Kafranis nowadays one of the largest villages of the region with a population of about 950; and together with nearby Tahmursa tand Farfan villages provides an ancient identity for the region (Zefrei,1977). According to geographical divisions of the country, the village is situated at the segment of Ben-rudof eastern Rouydasht, some $80 \mathrm{Kms}$ east of Isfahan, alongside with the IsfahanVarzaneh road. Its climate should be described as warm and dry, with cold and hard winters, and warm and dry summers.

\section{Description of Hadji Mosque}

With a foundation area of about $245 \mathrm{~m}$ squared and a different shape compared with other Iranian mosques, the Hadji mosque is situated at a short distance from Jame'hand Bazar Mosque of Kafran and at same direction of a water-course (FIG. 1). Iran's cultural heritage experts believe that it belongs to Safavid period (Ashrafi, 2006:4). The main body of the building includes a two- storied northern nave [=Shabestan], and a one-stratum southern nave (FIG.2). Numerous open Arches at the $2^{\text {nd }}$ floor have provided a vast interior- exterior visual connectivity, which together with various decorations of this part, provides a different view of the southern space.

\subsection{Spatial elements}

Bounded spaces of this building can be enumerated as follows: Little vestibule [=Hashti in Persian], the main space embracing the niche, the southern nave, and the restricted spaces of first storey. 


\subsubsection{Vestibule}

After crossing the eastern portico, one reaches to a little vestibule, which is separated from the main space of the building by a bricked-reticulated wall of a "half-storey"- height, while not disturbing the visual connection. It is of rectangular design which is stretched alongside the width of the main space. It is with this very feature that the observer is directed through two sides of its width in southern and northern fronts, to be terminated in a "back of the niche"- nave as well as the main space (northern nave). The vestibule also includes a stair-case terminating to the first storey of the main space and the roof of southern nave (FIG.2). This space lacks any kind of decoration; it is of barrel-vault shape and its inner surface is covered by gypsum.

\subsubsection{Northern nave}

The main space of the building has a rectangular shape and an east-to-west direction. It is "defined" by deep arches in the northern and western sides. On symmetry grounds, decorative arcades are replaced them in the southern side; while in the center of this side, the niche has been designed as a relatively deep Arch (FIGS.2\&3).

The most important feature of this part of the building is its "two-storeyedness"; the two are visually connected through a void which equals the area of the main space. From details of this part of the mosque, one can mention a little space in the northern side which opens the interior space of the mosque through a Bricked-reticulated wall, and whose outer Arch in the northern facade has nowadays been covered (FIGS.2\&13). Owing to open Arches of the first storey, the main space of the Mosque is indirectly open (FIG.3). Thus a bright and full-light space has been provided due to entering of light through Arches of two longitudinal sides (namely, southern and northern sides) of this part of the building. This fact has also provided a good possibility of air-conditioning, which should be considered as a favorable factor, due to warm weather of the region (FIGS.4\&5).

One of the main factors for greater importance of this space than the southern nave, is it's decorations; among most important of which one can mention the central Arch as well as over-the-Niche-space's stucco relieves; including shapes with bird-head designs (FIGS 6). Material used in this part of the building includes plaster and brick: plaster is used for coverings and decorations, and brick is used for reticulated walls as well as for the first-storey Arch- parapets.

\subsubsection{First storey spaces}

A stair case goes from the entering vestibule towards the roof of the southern nave. Encircling some 90 degrees clockwise, one enters the porticos built round the eastern, western and the northern sides of the rectangular void of the ${ }^{2 n d}$ storey. Their width equals the depth of lower storey arches; and in fact they have been built over the latter spaces. Porticos are semi-open-spaces which correlate the open space and interior ones. These are connected unusually through embedded opened spaces in the piers of arches. It seems that this "path" is a later modification/ addition produced by blocking the inter-piers-arches; as traces of original arches are still visible there (FIGS 7\&14). Parapets maid of latticed bricks don't play an important role in defining these spaces.

The portico's floor is paved with square-bricks of $25 \mathrm{~cm}$-side. Surfaces of this storey, as those of the main space of the mosque, have been covered by plaster, and have a four-folded-Arch structure.

\subsubsection{Southern nave}

Access to this space is provided, in addition of the vestibule, through a separate entrance in the western corner of the mosque (FIG 2). This nave is situated in the southern space of the mosque, in a western-eastern direction. It has a longer stretch than the main space; and deep arches have been at its two longitudinal sides to sub-divide the extra parts. The main difference between two main spaces is their light exposure; namely, while the main space is heavily exposed, the southern nave may only be regarded as semi-dark in spite of its longer length; it's light is just secured through a modest arch at the eastern side, as well as through tiny oculus of cloister vaults. This part lacks any decorative element and its surfaces are also covered by plaster (as those of the main space) (FIG.8). 


\subsection{Description of physical elements}

\subsubsection{Eastern facade}

The main facade of the building, including also its decorated entrance, is combined from a fully ornamented rectangular surface, with a simple square-shaped one. Their dimensions measure about $6.6 \times 9.3$ and $4.3 \times 3.9 \mathrm{~m}$ respectively. The main surface is constructed over a platform andincludes vertical- rectangular" low depth decorative arcades ". An entrance gate with piers and platforms at both sides is located at the center of eastern elevation surface, with full, "striped, bellow-the- roof" as well as plaster - stalactites ornamentations (FIG. 9).

Another important decorative element of this part is the so-called Tokhmehgozari (plaster engraving)which has been carried out within those stalactites in red (FIG. 10\&11). Plaster-engraving works of art of Safavid period are mostly belong to the periods of reigns of shah- Ismail the $1^{\text {st }}$ and shah Tahmasb (Salehikakhaki, et al., 2010); from which fact one can find an approximate time for the construction date of the building.Another important element of this facade is the bricked dado which have been designed with vertical bricks(FIG. 9).

It is noteworthy in the eastern facade that it's two surfaces are not in concordance with each other: their decorations and designs are different for example. This is one of the reasons to be adduced for the fact that the southern elevation is a later addition . It's simple surface lacks any sort of decoration and just includes a little arch-like window to secure the light of the nave (FIG. 11).

Materials used in the main part of the facade include brick, stone and the gypsum; of which the latter is used for covering of surfaces as well as for such ornamentations as squared-shaped bricks of $6 \times 25 \times 25 \mathrm{~cm}$ dimensions used in dado and in" reticulated -bricked-wall" of the decorative arcade. Stone is used for making the platform of the main part of the facade.

\subsubsection{Northern facade}

The northern facade, as the eastern one, is formed from a combination of surfaces of the main body of the building, and a surface of southern facade which includes the minor entrance to the building and approaches it directly. The most important difference of these two surfaces is also defined as the difference to be mentioned for the two major and minor parts in the western facade. The main part of the facade, and that of southern nave are defined in two and one storeys. The main space facade surface is partitioned by decorative arcades with a length equal to its height, stretched vertically, but with different widths (FIG12).

The most significant factor disturbing the smoothness of surfaces of this facade is the existence of two open arches with a relatively wide surfaces, which have provided the possibility of inter-outer-space interferences. At the corner of the western part of the building, where the plan deviates from a regular rectangular shape, and somewhere aligned with the $2^{\text {nd }}$ storey, a decorative arcade has been designed together with a bricked-reticulated wall. It is located at the end of the $2^{\text {nd }}$ storey of the main space (Fig13).

The variation of the design and decorations of these two parts of the facade, like those of eastern one, may be adduced as a reason for the fact that southern nave is a later addition. Cob has been used as covering layer of the main part of the facade; while after modern restorations, the surface is laid out with bricks. Bricks are used not only in brickworks, but also in making reticulated walls. Cob is also the main material used in the southern nave.

\section{The Space Analysis of the Hadji Mosque}

Of important issues in the space setting of the mosque, is the existence of a southern nave back of the niche, which is not usual in Iranian mosque-building practice, as making of the main niche marks the end of the mosque-building process(FIG2). The issue becomes more noteworthy when one sees that this nave is the largest space in the mosque designed for prayer ceremony; thus, once again the location of such an important place at the back of the main space's niche, confirms our hypothesis that identifies this space as a later addition.

More other evidences render this conjecture as a definite reality of which one can point out the differences in designing style, in decorations as well as in materials of southern nave, with the main body of the building (or the same northern nave). The point is also evident in the facade of these two parts in addition of their inner spaces (FIGS9\&13).

If we define "spatial clearness" as the "extent of visual domain as well as the measure of a visual correlation with the outer space "(Etemadi pour, ET. Al: 2012), then one can say that the most important difference of designing styles in these two spaces originates from their relative "spatial clearness". The northern nave includes numerous huge empty 
arches responsible for its excellent air-conditionings and light propagations; while, in contrast, the southern nave has a solid, dark, and closed space, lacking appropriate air \& light "dynamics". The greater dimensions of the nave makes this fact more apparent for this space.

As for decoration difference, elaborate decorations of the main space redolent of it's great importance; while, in contrast, the northern nave lacks any kind of decorative element which has greatly influenced it's spatial quality (FIGS3 \& 8).

The difference in style, ornamentations and material is also evident in exterior eastern and northern facades of the mosque. This difference is so high that an observer who has never seen the interior space, would guess that these two parts of the facade are internally separate. If the southern nave, namely the largest space in the building for prayer ceremony, turn out to be a later addition according to our hypothesis, then the only suitable space for this purpose would be the little northern nave whose size does not seem logical for the whole process of mosque-building. Thus we reach to our more fundamental assumption according to which the original using of the building was not a mosque and instead, has gradually changed to it in the course of time by adding a southern nave.

Spatial analysis of two storeys in the main body of the building also confirms its original non-religious using. Ground floor of the main part includes a modest space stretched in a vertical direction with respect to Muslims Qableh (and not towards it). Due to its very modest width, prayer ceremony could only performed in two rows. But because of decorations and design of the building, allocation of such spatially restricted part for it does not seem logical at all. The second point of the analysis is that the $2^{\text {nd }}$ storey space seems to be highly impractical for mosque using sand leaves it unused (FIG14).

There exist many apparent differences of this building with other usual ones in Iran;and even not a similar one may be found within the country. Of significant differences one can mention the lack of a dome, minaret, nave, portico and other usual spaces needed for prayer in Iranian mosque-architecture. Another point of inconsistency is the design of $2^{\text {nd }}$ storey, which is more usual in Iranian pavilion architecture (Kushk in Persian).

It should also be noted that the Hadjibuilding is located at the middle of the connecting path of Jameh and Bazar mosques of kafran village; while its distance from the both is also very low. This does not seem acceptable due to low population of the village; as this number of mosques is not appropriate for such a little ,low-populated village( FIG1).

On the other hand, the similarity of this building, irrespective of its later-added southern nave, to safavid pavilions, such as that of Hasht-beheshtis more evident( FIGS15\&16). Of most important similarity case is construction of the building over a platform, so as the open arches and porticos round the central void, have produced a good" spatial clearness"(defined above).Of course there also exists an important difference between this structure and Hasht-behesht pavilion, namely, the lack of suitable place as a temporary settlement. This prompts us not to ascribe a tourism-like-using for the original nucleus; but, instead, a formal ceremonial using which seems most probable: it was originally a center for local ruler or Khan's administrative activities.

\section{Concluding Remarks}

The results of the present study may be discussed within the context of the original using, and that the building could not be originally of religious type. The best reason for this assertion is the later-additional nature of southern nave ,because as the largest appropriate place for the prayer, it lacks least homogeneity with the main space of the building, from designing style, decoration, facade and light-passing arguments, to its location at the back of the niche .It's insufficient space for prayer ceremony, in spite the special design and decorations of the rest of the building, it's inappropriate direction with respect to that of the main body of the building and with respect to Qableh of Muslim people, and final, impractical nature of the $2^{\text {nd }}$ storey spaces when compared with the basic Iranian mosque-building traditions, all are among other reasons corroborating our hypothesis. The similarity of the building's form and design, while the added southern nave is ignored, to safavid pavilions, as well as lack of temporary settlement facilities within the mosque, strengthen our proposal ascribing a formal pavilion structure with an administrative using for the initial nucleus of the building.

\section{References}

Abu Na'imlsfahani, Hafez.1998. Zekr-e- Akhbar-e-Isfahan.Translation: NourallahKasaei.Tehran: Soroush press.

Ashrafi, Mohamadreza.2006. The registered report of Jame mosque of Kafran.

BastaniParizi, Mohamad Ebrahim.1997. Garkuye, sarzamininashenakhte bar karan-e- kavir.Isfahan: Ghazal press

Etemadipour, and Marzieh. Armin Bahramian.2012. "The comparison between GhasreGhajar and Takhtof Shiraz gardens" Journal of 
Iranian architecture1: 85-96.

HosseiniAbari, Hasan.2000.Zayanderoud azsarcheshme ta Mordab. Isfahan: Golha press.

Ibn-e-Khordazbeh, Obeid-e-lbn-e-Abdollah.1991.Almasalek vaAlmamalek.Translation:HosseinGharehChanlou. Tehran: Motarjem press. Ibn-e-Rosteh, Ahmad-e-lbn-e-Omar.1986. Alalagh-al-Nafiseh. Translation: HosseinGharehChanlou. Tehran: Amir kabir press.

Isfahani, Mohamad Mahdi-e-Ibn-e Mohamad Reza.1989.Nesf-e-Jahan fi Tarif-e- Alisfahan. Tehran: Amir Kabir press.

Jaberi Ansari, Mohamad Hasan.1999. Tarikh-e- Isfahanlsfahan: Ashal press.

Jenablsfahani, Ali.1893. Al-Isfahan. Isfahan: Golha press.

MostofiGazvini, Hamdoallah-e-lbn-e-Abibak-e-lbneNasr. Of $14^{\text {th }}$ century A.D. Nezhat-Al- Gholub.

RahaeiZefrei, MohamadHasan. 1977. "AsarTarikhiVaMazhabi-e- BakhseKouhpayeh-e- Isfahan" Journal of Vahid218:46-49.

RahaeiZefrei, MohamadHasan. 1977. "KouhpayehVaRoydashtein" Journal of Vahid214:40-42.

SalehiKakhki, Ahmad.2007. "Asare-e BejaMandeAzDoreyellkhani ta Teimouri Dar NahieyeRouydasht-e Isfahan". Journal of Literature and Human's sciences of Tehran university59: 51-78.

SalehiKakhki, Ahmad., SeyedMohamad Amin Emami,. And Hesam Aslani.2010. "FanavarihayeMoarragheGachiyeTokhmegozari Dar MemariedoreyeSafavieh". Journal of The historical Researches of Literature and Human's Sciences Faculty of Isfahan University2:63-80.

Sotudeh, Manouchehr.1965. Joghrafia-e Isfahan. Tehran: Tehran university press.

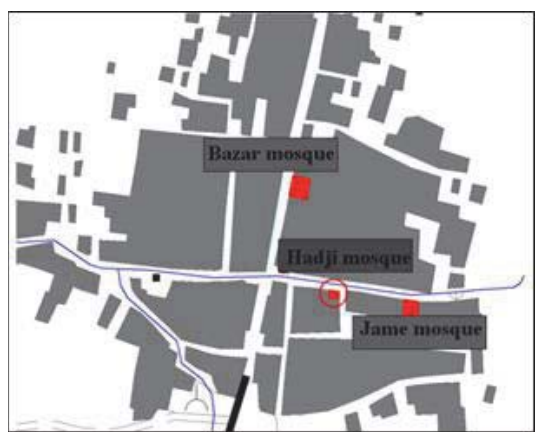

Figure 1. The position of mosques in Kafran village. Map by Geography administration.

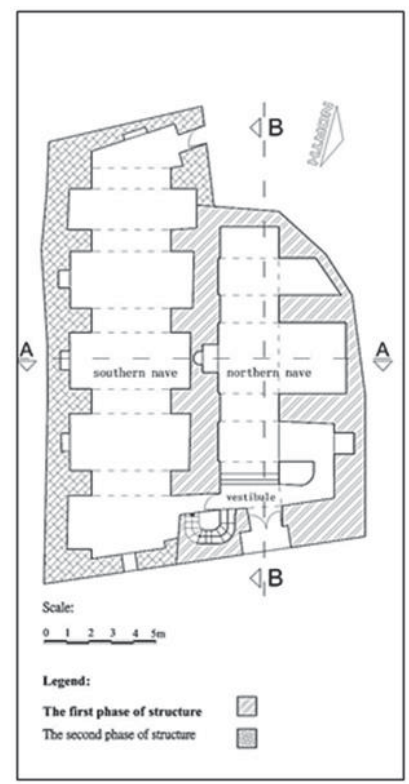

Figure 2. Ground floor of Haji mosque.Map by authors. 


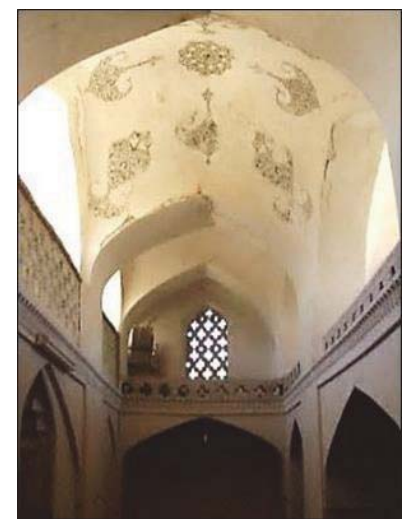

Figure 3. Northern nave of Haji building. Map by authors.

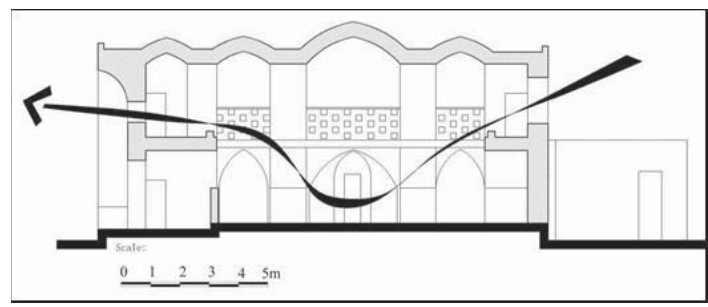

Figure 4. Section A-A (the graphical showing of ventilation). Map by authors.

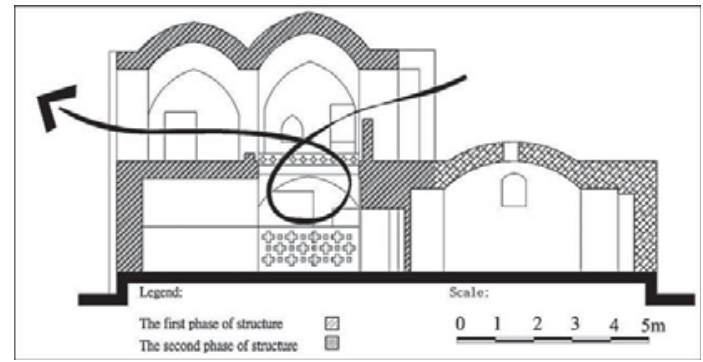

Figure 5. Section B-B (the graphical showing of ventilation). Map by authors.

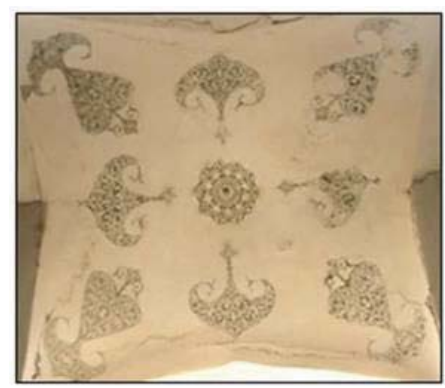

Figure 6. The internal decoration of central arch. Map by authors. 


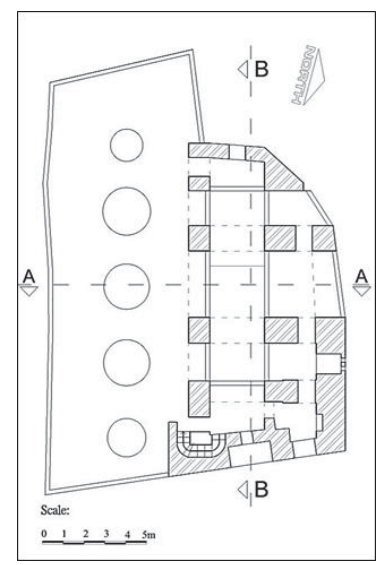

Figure 7. First floor plan of Hadjibuilding. Map by authors.

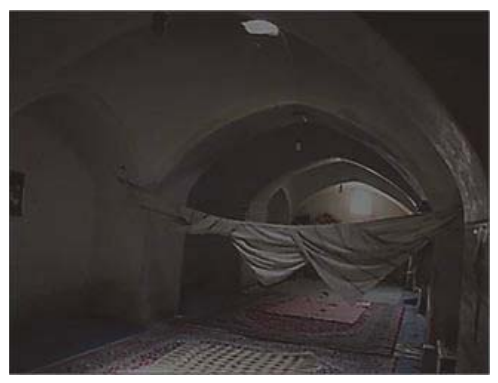

Figure 8. The southern nave of Hadjibuilding. Map by authors.

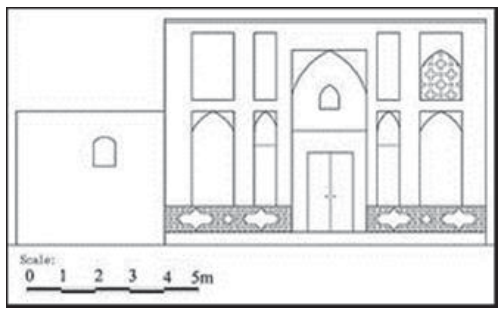

Figure 9. The eastern elevation of Hadjibuilding. Map by authors.

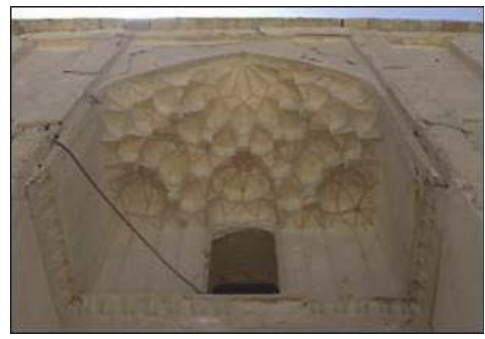

Figure 10. Plaster-stalactites ornamentations of portico. Map by authors. 


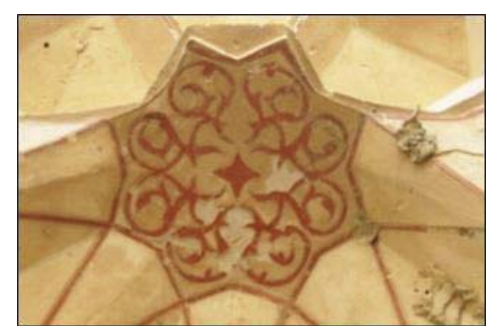

Figure 11. The decoration of portico's Tokhmegozari. Map by authors.

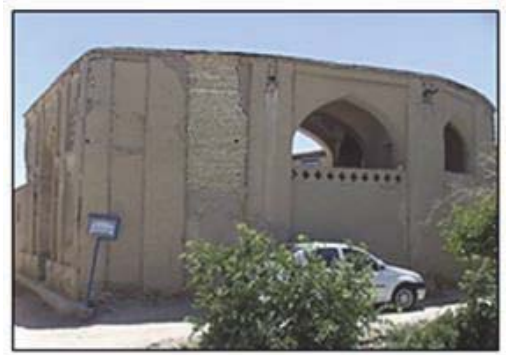

Figure 12. The main part of northern elevation. Map byauthors.

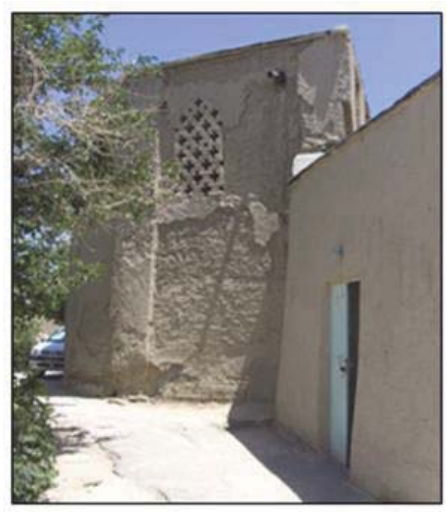

Figure 13. The subordinate part of northern elevation. Map byauthors.

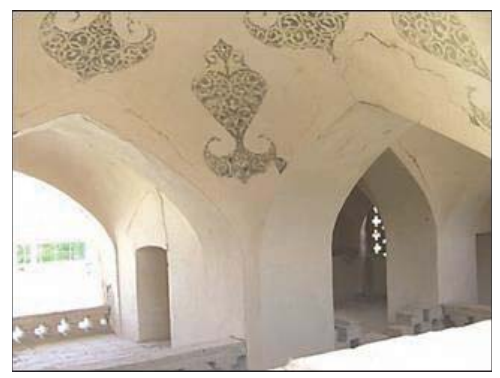

Figure 14. The spaces of first floor. Map byauthors. 


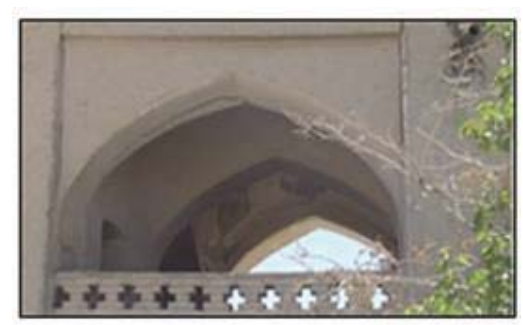

Figure 15. The one of open archs in Hadji building. Map by authors.

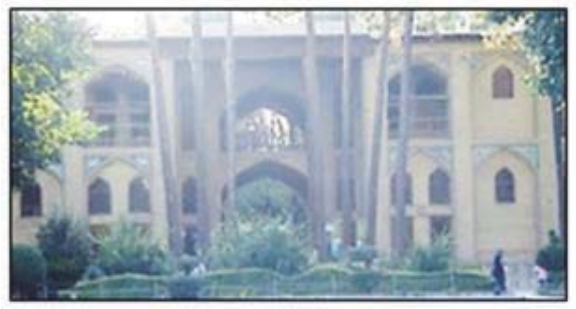

Figure 16. The open archs of Hassht-behesht pavilion. Map by authors. 